\title{
A systematic review on the correlation between skeletal and jawbone mineral
}

density in osteoporotic subjects.

Elena Calciolari ${ }^{1,2}$, Nikolaos Donos ${ }^{1}$, Jung-Chul Park ${ }^{3}$, Aviva Petrie ${ }^{4}$, Nikos Mardas ${ }^{1}$

${ }^{1}$ Periodontology Unit, UCL Eastman Dental Institute, London, UK

${ }^{2}$ Section of Periodontology, Implantology and Gnathology, Centre of Dentistry, University of Parma, Parma, Italy

${ }^{3}$ Department of Periodontology, College of Dentistry, Dankook University, Cheonan, South-Korea

${ }^{4}$ Biostatistics Unit, UCL Eastman Dental Institute, London, UK

Corresponding author

Prof Nikolaos Donos

Periodontology Unit, UCL Eastman Dental Institute

256, Gray's Inn Road

WC1X 8LD

London, UK

Email: n.donos@ucl.ac.uk

Tel.: 0044 (0)20 34561075

Fax: 0044 (0)20 34561137

Running title: Are jaws and skeletal bone density related in osteoporosis?

Keywords: bone density; densitometry; osteoporosis; bone disease, metabolic; jaw; review 


\section{Abstract}

Objectives The aim of this systematic review was to assess if the systemic skeletal reduction of bone mineral density (BMD) that characterizes osteoporotic subjects is also associated to a reduction of BMD in the jawbones.

Material and methods Two reviewers searched independently and in duplicate three databases up to May 2014 and assessed the risk of bias by using a tailored version of the Newcastle Ottawa scale (NOS). Only papers reporting either Pearson correlation coefficient or Spearman's rank correlation coefficient between skeletal and jawbone mineral density in more then five osteoporotic subjects were selected.

Results From 1763 citations, 64 full-text papers were screened and five papers that met the inclusion criteria were included in the final analysis. None of the included studies complied with all NOS criteria and since only two studies were eligible for meta-analysis, this was not performed..

Conclusions Only limited conclusions can be drawn from this systematic review, due to the small number of studies included, their heterogeneity and their high risk of bias. Future studies that take into consideration both upper and lower jaws, that use the same technique to measure skeletal and jaw BMD (ideally Dual-energy X-ray absorptiometry, DXA) and that account for confounding variables (such as medications/diseases affecting bone metabolism and demographics) are needed in order to provide more robust conclusions. 


\section{Introduction}

Osteoporosis is a common skeletal disease that progressively reduces bone mass and changes its micro architectural structure, thus increasing the risk of fractures. The World Health Organization (WHO) has defined osteoporosis as a level of bone mineral density (BMD), calculated with DXA (Dual-energy Xray absorptiometry) technique, 2.5 standard deviations (SD) or more below the average mean value for young healthy women (T-score $\leq-2.5$ ) (Kanis, Melton et al. 1994, Kanis, McCloskey et al. 2013). The reference range recommended for calculating the $\mathrm{T}$ score is the National Health and Nutrition Examination Survey (NHANES) III database for femoral neck measurements in young Caucasian women (Looker, Wahner et al. 1998) and for this reason femoral neck is commonly used as the reference site. DXA scan is considered the gold standard for measuring BMD and diagnosing osteoporosis for its reproducibility, short scan times, large normative data and very low doses of radiation (Blake and Fogelman 2007), although other techniques such as quantitative ultrasound (QUS), quantitative computed tomography (QCT), peripheral DXA, digital X-ray radiogrammetry and radiographic absorptiometry are also commonly employed (Kanis, McCloskey et al. 2013).

Approximately $30 \%$ of all American and European post-menopausal women have osteoporosis and more than $40 \%$ of them are likely to experience one or more fragility fractures during their remaining lifetime (Melton, Chrischilles et al. 1992, Reginster and Burlet 2006). According to Johnell et al (Johnell and Kanis 2006), osteoporosis in Europe accounts for more deaths and morbidity than any other neoplastic disorder, save only for lung cancer, thus making the burden of osteoporosis extremely alarming.

As the number of osteoporotic patients requiring dental care is increasing, it would be important to know if osteoporosis is associated with a reduction of bone mass and density also in the jawbones. This could have important clinical implications, related for example to the success/survival and osseointegration of dental implants, to the success of bone regeneration therapies or to the risk of an increased bone loss in subjects affected by periodontitis (Blomqvist, Alberius et al. 1996, August, Chung et al. 2001, Gondim, Aun et al. 2013, Passos, Vianna et al. 2013). Although the evidence from the literature is only modest, it is plausible to hypothesize that osteoporotic-induced systemic bone loss may include also bone loss at the jaws, as bones of the skeleton. Pre-clinical studies in ovariectomized animals reported that estrogen deficiency could determine a decrease in bone volume and alterations in the trabecular structure of the mandibular condyle (Kuroda, Mukohyama et al. 2003, Kosugi, Yonezu 
et al. 2013), in the inter-radicular septa of molar alveolar bone (Tanaka, Ejiri et al. 2002, Dai, Zhang et al. 2014) and also an increase in mandibular cortical porosity (Dvorak, Reich et al. 2011). A correlation between lumbar and alveolar bone density in ovariectomized monkeys has also been documented (Anwar, Tanaka et al. 2007). Some clinical studies reported that there is an increased alveolar bone resorption in osteoporotic versus non-osteoporotic edentulous patients (Hirai, Ishijima et al. 1993, Singhal, Chand et al. 2012) and that medications affecting systemic bone density (like hormone replacement therapy and bisphosphonates) are associated with a slower loss of alveolar bone (Graziani, Rosini et al. 2008) and improved periodontal parameters (Lane, Armitage et al. 2005, Lopez-Marcos, Garcia-Valle et al. 2005). However, other clinical studies did not confirm the influence of systemic bone mineral density on the resorption of edentulous jaws (Elders, Habets et al. 1992, Ozola, Slaidina et al. 2011, Springe, Slaidina et al. 2014).

Some clinical studies have investigated the relationship between bone density measured in different systemic skeletal sites and in the jawbones in subjects with different T scores. Although many of these studies have found a positive correlation (Horner, Devlin et al. 1996, Jonasson, Bankvall et al. 2001, Drozdzowska, Pluskiewicz et al. 2002, Takaishi, Okamoto et al. 2005, Erdogan, Incki et al. 2009, Vishwanath, Kumar et al. 2011, Makker, Singh et al. 2012, Esfahanizadeh, Davaie et al. 2013), others have reported that jawbone density is not, or only little, correlated to the density in other anatomic sites (Kingsmill and Boyde 1999, Jonasson 2009, Holahan, Wiens et al. 2011). A few studies did not manage to find differences in jawbone density between normal and osteopenic/osteoporotic subjects (Mohajery and Brooks 1992, Gulsahi, Paksoy et al. 2010).

The heterogeneity between the available studies may have contributed to this wide variability of results. In fact, in the published studies different techniques to measure bone density were adopted, dentate and edentulous areas were often pulled together and populations with different demographic characteristics were evaluated without accounting for confounding variables. In addition, the methods used for bone density measurement often had insufficient precision and accuracy.

Despite the contradicting results, a recent review suggested that osteoporotic bone should be regarded as equivalent to Type IV, according to Lekholm and Zarb classification (Lekholm, Zarb et al. 1985) and that, conforming to the limited available evidence, the clinician may also consider to allow a longer healing period for implant osseointegration before prostheses insertion in osteoporotic patients (GaettiJardim, Santiago-Junior et al. 2011). 
As a dedicated software for DXA measurement of the jaws does not exist, it has been proposed to adapt the forearm software to the mandible, despite evident practical difficulties (Horner, Devlin et al. 1996). Many other different techniques have been used to measure jawbone density, such as dualphoton absorptiometry (DPA), quantitative computer tomography (QCT), film densitometry, pixel intensity (PI), fractal dimension and visual inspection (von Wowern 1974, Klemetti, Kolmakov et al. 1993, Law, Bollen et al. 1996, Lindh, Horner et al. 2008), thus making comparisons among the studies very difficult. Bodic et al (Bodic, Amouriq et al. 2012) reported that computer tomography (CT) remains the most appropriate technique for the evaluation of mandibular bone density but they didn't find a correlation between mandibular and iliac bone in 20 human cadavers. On the contrary, a recent study of Chai et al (Chai, Chau et al. 2014) found that mandibular bone density measured in Hounsfield units (HU) with CT scans in edentulous subjects between 50 to 80 years of age has a modest but significant correlation with T scores and the authors suggested HU cut-offs for identifying osteoporotic subjects.

The aim of this systematic review was to summarize and critically appraise today's knowledge on the correlation between systemic skeletal BMD and BMD of the jaws in osteoporotic subjects. In other words, we were interested to clarify if osteoporosis could also affect the jawbones. Although previous literature reviews have addressed the potential detrimental effect of osteoporosis on jawbones, they mainly focused on the outcomes of dental implants in osteoporotic patients (Tsolaki, Madianos et al. 2009, Gaetti-Jardim, Santiago-Junior et al. 2011), without answering the question whether jawbones behave like the other bones of the skeleton in osteoporotic conditions. This will give us useful information in the attempt to consider osteoporosis from a multidisciplinary point of view and it may provide guidelines for future studies.

\section{Materials \& Methods}

The Preferred Reporting Items for Systematic reviews and Meta-Analyses (PRISMA) statement (Moher, Liberati et al. 2009) was followed.

\section{Focused question}

The question addressed was the following: "Is jawbone mineral density correlated to skeletal bone mineral density in osteoporotic subjects?”

Eligibility criteria 
Observational studies assessing the correlation between jaw (either mandible or upper jaw) and skeletal BMD in osteoporotic subjects were considered. Only studies with at least 5 osteoporotic patients were selected, in order to exclude individual case reports. No restriction related to the technique adopted to measure bone density was initially applied in order to avoid omitting relevant data. However, since the sensitivity and specificity of the radiographic technique is crucial for reflecting bone density changes, it was taken into consideration and described in details for all the included studies in the quality data analysis of the result and discussion sections and in Table 3. The primary outcome of this review was to determine if in osteoporotic subjects the reduced systemic skeletal BMD is also associated with a reduced $\mathrm{BMD}$ in the jaws, therefore the studies had to report one of the following measures: the Pearson correlation coefficient or the non-parametric Spearman's rank correlation coefficient in osteoporotic subjects. Both coefficients measure the degree to which two variables are related, the first one applies to normally distributed variables and linear relations, whilst the second one is a nonparametric measure of statistical dependence and measures the monotonic relationship between two variables (Zou, Tuncali et al. 2003).

\section{Search strategy, selection of trials and data abstraction}

The research strategy included terms related to the population and the intervention investigated in this review and was performed in three databases, MEDLINE via OVID, EMBASE and The Cochrane Database (including the Central Register of Controlled Trials (CENTER)), updated to May 2014. In addition, bibliographies of review articles on this topic and of all the studies included for data extraction were screened and a hand search was performed in the major journals of the field (Bone, Journal of Bone and Mineral Research, Osteoporosis International, Menopause, Oral Surgery, Oral Medicine, Oral Pathology, Oral Radiology and Endodontics, Journal of Prosthetic Dentistry). In an attempt to include also unpublished data, a specific theses database, www.theses.com/, was additionally screened and soon-to-be-published manuscripts were searched by contacting research groups with an interest in osteoporosis and in oral consequences of osteoporosis. Finally, Grey Literature was searched in opensigle.inist.fr. No language restrictions were applied. The search strategy for MEDLINE and EMBASE used a combination of MeSH terms and text words which were combined as Population AND Intervention (Table 1). Due to the large volume of literature on this topic, a three-stage screening was applied to increase the precision of screening. All stages (titles, 
abstract, full-text) were carried out in duplicate and independently by two reviewers (EC and JCP) and the level of agreement at each of the three-stages was calculated using Kappa statistics. Any disagreement was resolved by discussion and, if necessary, a third reviewer (NM) was consulted. At the stage of full-text screening, a data extraction form was completed to check eligibility of the studies and, if eligible, to collect detailed information about population, intervention and outcomes. Reasons for study exclusion were also recorded (Tab. 2). Any ambiguous or incomplete data were further investigated by contacting the researchers responsible for the work.

\section{Quality assessment}

The methodological quality of the studies was assessed independently and in duplicate by two reviewers (EC, JCP), as part of the data extraction process. The Newcastle-Ottawa Scale (NOS) was applied. This tool arose by the combined efforts of the Universities of Newcastle and Ottawa to assess the quality of non-randomized studies and was endorsed for use in systematic reviews of nonrandomized studies by The Cochrane Collaboration (Higgins and Green updated March 2011). The NOS provides predefined criteria covering three domains (selection of participants, comparability of study groups and ascertainment of exposure/outcome), some of which have to be further specified according to the aim of the review. We specified these criteria and tailored the tool for cross-sectional studies in a consensus meeting with all authors before assessing the studies.

\section{Data synthesis and statistical analysis}

Correlation coefficients were extracted from the studies meeting inclusion and exclusion criteria and confidence intervals were obtained through Fisher's z transformation. Following statistician's advice, we decided to perform meta-analysis only in case we found at least three papers that reported the Pearson correlation coefficient and which measured systemic skeletal BMD in the same anatomic site.

\section{Results}

\section{Studies included}

Four studies were identified through the database search and one additional study was retrieved through hand-search and bibliography check that met the inclusion/exclusion criteria (Figure 1). The reasons for exclusion of the studies at the level of full-text screening are reported in Table 2. Kappa statistics showed a high level of agreement between the reviewers $(K>0.90)$ at all three stages of 
screening. All the included studies had a cross-sectional design and involved only post-menopausal osteoporotic women (Table 3).

The systemic skeletal sites evaluated by the studies and the techniques applied to measure BMD were pretty heterogeneous (Table 3). The first study of Kribbs et al (Kribbs, Smith et al. 1983) measured systemic skeletal BMD only at the forearm (at one tenth, S1, and one fifth, S2, of its length) by using single photon absorptiometry (SPA), while the second study from the same research group (Kribbs, Chesnut et al. 1989) considered also the lumbar spine, whose BMD was measured by using both dual photon absorptiometry (DPA) and computed Tomography (CT). Cakur et al (Cakur, Sahin et al. 2008) measured systemic skeletal BMD at the lumbar spine by using DXA, while the same group (Cakur, Dagistan et al. 2009) one year later and the group of Klemetti (Klemetti, Vainio et al. 1993) considered both lumbar spine and femur neck BMD and assessed them through DXA scan

Three studies used oral radiographs with an aluminum step wedge to measure mandibular density (Kribbs, Smith et al. 1983, Kribbs, Chesnut et al. 1989, Cakur, Sahin et al. 2008), and another one used a quantitative computed tomography QCT scan (Klemetti, Vainio et al. 1993). Cakur et al (Cakur, Dagistan et al. 2009) were the only ones that used the same technique (DXA scan) to measure skeletal and mandible BMD.

Two studies reported the use of Spearman's rank correlation coefficient, with pretty different results: the first study of Cakur et al (Cakur, Sahin et al. 2008) found a significant correlation between BMD at the lumbar spine and BMD at the mandible $\left(\mathrm{r}_{\mathrm{s}}=0.434, \mathrm{p}=0.030\right)$, whilst the same group one year later did not manage to find a significant correlation between lumbar and femur BMD and mandibular BMD $\left(r_{s}=0.017\right.$ and $r_{s}=-0.054$ respectively) (Cakur, Dagistan et al. 2009). The remaining three studies used the Pearson correlation coefficient. Klemetti et al (Klemetti, Vainio et al. 1993) distinguished between the most and the average osteoporotic subjects according to the BMD values of the femur neck obtained by a dual-energy $\mathrm{x}$-ray transmission apparatus. In particular, in the most osteoporotic group (BMD at femur neck $<920 \mathrm{mg} / \mathrm{cm}^{2}$ ), they reported significant correlation coefficients between corticalbuccal and cortical-lingual mandibular BMD and femur BMD (respectively $\mathrm{r}=0.51, \mathrm{p}<0.05$ and $\mathrm{r}=0.54, \mathrm{p}<0.001)$. Conversely, they did not find a significant correlation between corticalbuccal/lingual mandibular BMD and lumbar BMD. Both studies of Kribbs et al (Kribbs, Smith et al. 1983, Kribbs, Chesnut et al. 1989) reported a significant correlation between BMD at the forearm and at the mandible (respectively $r=0.594$ with $p<0.001$ and $r=0.34$ with $p<0.01$ ). 
All included studies measured the density of the jaws in the mandible and no study considered the maxilla. Cakur et al studies took into consideration a $10 \mathrm{X} 10 \mathrm{~mm}^{2}$ area of the mandible free of teeth and roots (Cakur, Sahin et al. 2008, Cakur, Dagistan et al. 2009), Klemetti et al measured the cortical and trabecular mandibular density distally to the mental foramen (Klemetti, Vainio et al. 1993) and Kribbs et al measured mandibular density either around mandibular teeth (dentate subjects) or distally to the mental foramen (edentulous subjects) (Kribbs, Smith et al. 1983, Kribbs, Chesnut et al. 1989). Previous studies assessing BMD of the mandible considered various areas of interest, located in the ramus (Horner, Devlin et al. 1996, Gulsahi, Paksoy et al. 2010, Esfahanizadeh, Davaie et al. 2013), the body of the mandible (Horner, Devlin et al. 1996, Drozdzowska, Pluskiewicz et al. 2002, Gulsahi, Paksoy et al. 2010, Makker, Singh et al. 2012, Esfahanizadeh, Davaie et al. 2013), the symphysis region (Horner, Devlin et al. 1996, Gulsahi, Paksoy et al. 2010) or the interdental areas (Jonasson, Bankvall et al. 2001, Takaishi, Okamoto et al. 2005, Erdogan, Incki et al. 2009, Jonasson 2009).

\section{Assessment of methodological quality}

There were no studies complying with all NOS criteria. Both studies of Cakur et al had the highest NOS score with seven out of eleven stars, whilst the two studies of Kribbs et al collected only three out of eleven stars (Table 4). Most of the quality issues were related to the selection of the subjects (either the osteoporotic condition or the representativeness of the subjects were not well-defined) and to the exposure (most studies did not use the same technique to measure skeletal and mandible BMD and they did not define if there was an appropriate interval of time between the two ascertainments).

\section{Meta-analysis}

Only three studies reported Pearson correlation coefficients (Kribbs, Smith et al. 1983, Kribbs, Chesnut et al. 1989, Klemetti, Vainio et al. 1993) (we assumed that both Kribbs studies used it), but only the two Kribbs studies compared BMD at the same skeletal site (forearm) with mandible BMD and, as a consequence, we had to exclude Klemetti study. Meta-analysis was therefore not performed.

\section{Discussion}

Four out of the five studies included in this review reported a significant correlation between BMD measured at different systemic skeletal sites and mandible BMD. Cakur et al (Cakur, Dagistan et al. 
2009) study is the only one that did not confirm this correlation. However, we need to be very cautious on drawing conclusions, as these five studies were hardly comparable, since they used different techniques to measure skeletal and mandible BMD and they took into consideration different anatomic sites.

The meta-analysis was not performed, since we retrieved only on two studies that compared skeletal and jawbone BMD measured at the same anatomical sites and both did not have a high methodological quality..

Although there are no precise guidelines on how to interpret correlation coefficient results, the magnitude of correlation is usually considered in relation to the p-values (which is influenced by the sample size) and the $\mathrm{r}$ squared. The correlation coefficient can take values from -1 to 1 , where 1 is the perfect correlation. The four included studies that found a positive correlation between mandible and skeletal BMD reported correlation coefficients ranging from 0.3 to 0.697 (Kribbs, Smith et al. 1983, Kribbs, Chesnut et al. 1989, Klemetti, Vainio et al. 1993) (Table 3). In the study that did not find a significant correlation, a Spearman's rank correlation coefficient ranging from -0.054 to 0.017 was reported (Cakur, Dagistan et al. 2009) (Table 3).

Several studies had also to be excluded during the screening stages because they did not distinguish between osteoporotic and healthy patients when reporting the correlation coefficients between skeletal and jaw BMD, thus further limiting the possibility of drawing robust conclusions.

Another limitation of this review is related to the fact that all studies considered only mandibular BMD, without taking into account the maxilla. It is well known that in osteoporotic subjects bone loss is not uniform and that the trabecular bone is earlier and more deeply affected than the cortical bone (Clarke and Khosla 2010, Khosla 2013). The mandible has a better resemblance with the femur neck (Devlin, Sloan et al. 1994, Devlin and Whelton 2013), where fractures are primarily caused by a loss in cortical rather than trabecular bone (Bell, Loveridge et al. 1999, Crabtree, Loveridge et al. 2001). Considering that the maxilla is mainly made of trabecular bone, it is likely that bone density measured at this site would have been better related to skeletal osteoporosis. However, the lack of stable referral points (like the mental foramen in the mandible) makes it challenging to evaluate standardized sites in the maxilla.

According to Gulsahi et al, BMD is the highest in the mandibular anterior region and lowest in the maxillary anterior and premolar regions (Gulsahi, Paksoy et al. 2010). 
A recent study described a decrease in jawbone density assessed by DXA scan in osteoporotic subjects and observed the lowest level of density in the anterior region of the maxilla (Esfahanizadeh, Davaie et al. 2013). In addition, they found a positive correlation $(\mathrm{p}<0.05)$ between BMD at various regions of the jawbones and femur and vertebrae BMD.

When dealing with jawbones it should also be borne in mind that they display unique anatomic characteristics in comparison with other bones of the skeleton, owing for example to their special relationship with teeth and the distinction between the more stable basal bone and the alveolar bone, which atrophies after teeth are lost (Tallgren 2003, Pietrokovski, Starinsky et al. 2007). Alveolar bone arises from the dental follicle (neural crest origin) and is therefore physiologically different from all other bones (Duailibi, Duailibi et al. 2006). It may be hypothesized that these and other anatomical/physiological peculiarities of the jaws can somehow account for differences in bone metabolism response (Seldin 2012). Therefore, applying the current reference standards for the diagnosis of skeletal osteoporosis (based on the NHANES III study (Looker, Wahner et al. 1998)) also to the diagnosis of jawbone osteoporosis, could be misleading. Further research on jawbone BMD in a large and representative population is necessary in order to develop a jawbone $\mathrm{T}$ score or $\mathrm{Z}$ score that could probably be used, similarly to the available skeletal scores, for the diagnosis of jawbone osteoporosis.

Some researchers pointed that the basal area of the mandible posterior to the mental foramen is probably the only part of the jaws with reasonably suitable characteristics to be a standard site for BMD measurements, since it has small inter- and intra-individual variations in anatomical size, shape, bone structure ad function (von Wowern 2001).

Among the five studies included in this review, three (Klemetti, Vainio et al. 1993, Cakur, Sahin et al. 2008, Cakur, Dagistan et al. 2009) took into consideration edentulous areas of the mandible and the last two studies (Kribbs, Smith et al. 1983, Kribbs, Chesnut et al. 1989) pulled together edentulous and dentate areas without distinguishing the results.

All the included studies recruited only osteoporotic post-menopausal women, therefore it is not possible to generalize the results to other forms of osteoporosis or to men.

\section{Conclusions}

The small number and heterogeneity of the retrieved studies did not allow clarifying if skeletal osteoporosis is associated also to osteoporosis in the jawbones. We recommend that future studies 
should use the same technique to measure skeletal and jaw BMD (ideally DXA scan would be the best option, since it is considered the gold-standard for osteoporosis diagnosis), that they should possibly consider both upper and lower jaws and distinguish between basal and alveolar bone.

Since it is overall accepted to use hip and lumbar spine as references for diagnosing osteoporosis, it would be probably more useful to compare jawbone density with the density of these bones.

Future efforts should be dedicated to address this correlation not only in post-menopausal women but also in men and in patients with secondary osteoporosis, in order to have a wider picture of this possible association. Whether a correlation between jaws and other bones of the skeleton is confirmed, future studies may be able to identify customized thresholds for $\mathrm{T}$ and $\mathrm{Z}$ scores also for the jawbones. 


\section{References}

Alman, A. C. J., L. R.; Calverley, D. C.; Grunwald, G. K.; Lezotte, D. C.; Hokanson, J. E. (2012) Diagnostic capabilities of fractal dimension and mandibular cortical width to identify men and women with decreased bone mineral density. Osteoporosis International 5:1631-1636.

Alonso, M. B. C. C. O., M. L.; Pedrosa, E. F. N. C.; Ambrosano, G. M. B.; Watanabe, P. C. A.; HaiterNeto, F. (2012) Relationship between bone mineral density and trabecular bone pattern in postmenopausal brazilian women by using dual x-rayabsorptiometryand digital panoramic radiographs. Archives of Osteoporosis S158. IOF Regionals, $1^{\text {st }}$ Latin America Osteoporosis Meeting Sao Paulo Brazil.

Amorim, M. A. L. T., L.; Jorgetti, V.; Pereira, R. M. R. (2006) Comparative study of axial and femoral bone mineral density and parameters of mandibular bone quality in patients receiving dental implants. Osteoporosis International 10:1494-1500.

Amorim, M. A. L. T., L.; Jorgetti, V.; Pereira, R. M. R. (2007) Erratum: Comparative study of axial and femoral bone mineral density and parameters of mandibular bone quality in patients receiving dental implants. Osteoporosis International 5:703-709.

Anwar, R. B., Tanaka, M., Kohno, S., Ikegame, M., Watanabe, N., Ali, M. N. \& Ejiri, S. (2007) Relationship between porotic changes in alveolar bone and spinal osteoporosis. Journal of dental research 86: 52-57.

Ardakani, F. E. O., M. B.; Hesami, S. (2012) Digital panoramic radiography as a usefull tool for detection of bone loss: A comparative study,. Rheumatology i21-i22. Conference: Excellence in Rheumatology 2012, Madrid Spain.

August, M., Chung, K., Chang, Y. \& Glowacki, J. (2001) Influence of estrogen status on endosseous implant osseointegration. Journal of oral and maxillofacial surgery 59: 1285-1289; discussion 12901281.

Bakalczuk, M. B., S.; Rozylo, T. K.; Kleinrok, J. (2006) The influence of hormonal replacement therapy on alveolar ridge bone in perimenopuasal women. Przeglad Menopauzalny 1:47-50.

Bell, K. L., Loveridge, N., Power, J., Garrahan, N., Meggitt, B. F. \& Reeve, J. (1999) Regional differences in cortical porosity in the fractured femoral neck. Bone 24: 57-64.

Blake, G. M. and I. Fogelman (2007). The role of DXA bone density scans in the diagnosis and treatment of osteoporosis. Postgrad Med J 83: 509-517.

Blomqvist, J. E., Alberius, P., Isaksson, S., Linde, A. \& Hansson, B. G. (1996) Factors in implant integration failure after bone grafting: An osteometric and endocrinologic matched analysis. International journal of oral and maxillofacial surgery 25: 63-68.

Bodic, F., Amouriq, Y., Gayet-Delacroix, M., Maugars, Y., Hamel, L., Basle, M. F. \& Chappard, D. (2012) Relationships between bone mass and micro-architecture at the mandible and iliac bone in edentulous subjects: A dual x-ray absorptiometry, computerised tomography and microcomputed tomography study. Gerodontology 29: e585-594.

Bozic, M. Hren, N.I. (2006) Osteoporosis and mandibles. Dentomaxillofacial Radiology 3:178-184.

Buyukkaplan, U. S. G., Musa Ustun; Yildiz, Mustafa; Gumus, Burcin Askim (2012) Comparison of mandibular bone mineral density in osteoporotic, osteopenic and normal elderly edentulous subjects measured by the dual-energy x-ray absorptiometry technique. Journal of Prosthodontics 6:e1098-1102.

Byung, D. L. W., S. C. (2005) Age and trabecular features of alveolar bone associated with osteoporosis. Oral Surgery, Oral Medicine, Oral Pathology, Oral Radiology, and Endodontics 1:9298. 
Cakur, B., Dagistan, S., Sahin, A., Harorli, A. \& Yilmaz, A. (2009) Reliability of mandibular cortical index and mandibular bone mineral density in the detection of osteoporotic women. Dento maxillo facial radiology 38: 255-261.

Cakur, B., Sahin, A., Dagistan, S., Altun, O., Caglayan, F., Miloglu, O. \& Harorli, A. (2008) Dental panoramic radiography in the diagnosis of osteoporosis. J Int Med Res 36: 792-799.

Chai, J., Chau, A. C., Chu, F. C. \& Chow, T. W. (2014) Diagnostic performance of mandibular bone density measurements in assessing osteoporotic status. The International journal of oral \& maxillofacial implants 29: 667-674.

Clarke, B. L. \& Khosla, S. (2010) Physiology of bone loss. Radiol Clin North Am 48: 483-495.

Crabtree, N., Loveridge, N., Parker, M., Rushton, N., Power, J., Bell, K. L., Beck, T. J. \& Reeve, J. (2001) Intracapsular hip fracture and the region-specific loss of cortical bone: Analysis by peripheral quantitative computed tomography. Journal of Bone \& Mineral Research 16: 1318-1328.

Dai, Q. G., Zhang, P., Wu, Y. Q., Ma, X. H., Pang, J., Jiang, L. Y. \& Fang, B. (2014) Ovariectomy induces osteoporosis in the maxillary alveolar bone: An in vivo micro-ct and histomorphometric analysis in rats. Oral Dis 20: 514-520.

Devlin, H., Sloan, P. \& Luther, F. (1994) Alveolar bone resorption: A histologic study comparing bone turnover in the edentulous mandible and iliac crest. The Journal of prosthetic dentistry 71: 478-481.

Devlin, H. \& Whelton, C. (2013) Can mandibular bone resorption predict hip fracture in elderly women? A systematic review of diagnostic test accuracy. Gerodontology.

Devlin, H. K., Kety; Mitsea, Anastasia; Jacobs, Reinhilde; Lindh, Christina; van der Stelt, Paul; Marjanovic, Elizabeth; Adams, Judith; Pavitt, Susan; Horner, Keith (2007) Diagnosing osteoporosis by using dental panoramic radiographs: The osteodent project. Oral Surgery, Oral Medicine, Oral Pathology, Oral Radiology and Endodontology 6:821-828.

Drozdzowska, B., Pluskiewicz, W. \& Tarnawska, B. (2002) Panoramic-based mandibular indices in relation to mandibular bone mineral density and skeletal status assessed by dual energy $\mathrm{x}$-ray absorptiometry and quantitative ultrasound. Dentomaxillofacial radiology 31: 361-367.

Duailibi, S. E., Duailibi, M. T., Vacanti, J. P. \& Yelick, P. C. (2006) Prospects for tooth regeneration. Periodontol 2000 41: 177-187.

Dvorak, G., Reich, K. M., Tangl, S., Goldhahn, J., Haas, R. \& Gruber, R. (2011) Cortical porosity of the mandible in an osteoporotic sheep model. Clinical Oral Implants Research 22: 500-505.

Elders, P. J. M., Habets, L. L. M. H., Netelenbos, J. C., Vanderlinden, L. W. J. \& Vanderstelt, P. F. (1992) The relation between periodontitis and systemic bone mass in women between 46 and 55 years of age. Journal of clinical periodontology 19: 492-496.

Erdogan, O., Incki, K. K., Benlidayi, M. E., Seydaoglu, G. \& Kelekci, S. (2009) Dental and radiographic findings as predictors of osteoporosis in postmenopausal women. Geriatrics \& gerontology international 9: 155-164.

Esfahanizadeh, N., Davaie, S., Rokn, A. R., Daneshparvar, H. R., Bayat, N., Khondi, N., Ajvadi, S. \& Ghandi, M. (2013) Correlation between bone mineral density of jaws and skeletal sites in an iranian population using dual x-ray energy absorptiometry. Dent Res J (Isfahan) 10: 460-466.

Gaetti-Jardim, E. C., Santiago-Junior, J. F., Goiato, M. C., Pellizer, E. P., Magro-Filho, O. \& Jardim Junior, E. G. (2011) Dental implants in patients with osteoporosis: A clinical reality? The Journal of craniofacial surgery 22: 1111-1113.

Geraets, W. G. M. V., J. G. C.; van der Stelt, P. F.; Horner, K.; Lindh, C.; Nicopoulou-Karayianni, K.; Jacobs, R.; Marjanovic, E. J.; Adams, J. E.; Devlin, H. (2008) Selecting regions of interest on intraoral radiographs for the prediction of bone mineral density. Dentomaxillofacial Radiology 7:375-379. 
Gondim, V., Aun, J., Fukuda, C. T., Takayama, L., Latorre Mdo, R., Pannuti, C. M., Rodrigues Pereira, R. M. \& Romito, G. A. (2013) Severe loss of clinical attachment level: An independent association with low hip bone mineral density in postmenopausal females. Journal of periodontology 84: 352-359.

Graziani, F., Rosini, S., Cei, S., La Ferla, F. \& Gabriele, M. (2008) The effects of systemic alendronate with or without intraalveolar collagen sponges on postextractive bone resorption: A single masked randomized clinical trial. The Journal of craniofacial surgery 19: 1061-1066.

Gulsahi, A., Paksoy, C. S., Ozden, S., Kucuk, N. O., Cebeci, A. R. \& Genc, Y. (2010) Assessment of bone mineral density in the jaws and its relationship to radiomorphometric indices. Dentomaxillofacial radiology 39: 284-289.

Hedstrom, L. B., A.; Bergh, H. (2010) The relation between bone mineral density in the heel and pixel intensity in the mandibular jaw bone among elderly women. Dentomaxillofacial radiology 7:409-413.

Higgins, P. \& Green, S. (updated March 2011) Cochrane handbook for systematic reviews of interventions. London, Uk: The Cochrane Collaboration.

Hirai, T., Ishijima, T., Hashikawa, Y. \& Yajima, T. (1993) Osteoporosis and reduction of residual ridge in edentulous patients. The Journal of prosthetic dentistry 69: 49-56.

Holahan, C. M., Wiens, J. L., Weaver, A., Assad, D. \& Koka, S. (2011) Relationship between systemic bone mineral density and local bone quality as effectors of dental implant survival. Clinical implant dentistry and related research 13: 29-33.

Horner, K., Devlin, H., Alsop, C. W., Hodgkinson, I. M. \& Adams, J. E. (1996) Mandibular bone mineral density as a predictor of skeletal osteoporosis. The British journal of radiology 69: 1019-1025.

Horner, K. D., H. (1992) Clinical bone densitometric study of mandibular atrophy using dental panoramic tomography. Journal of dentistry 1:33-37.

Horner, K. D., H. (1998) The relationship between mandibular bone mineral density and panoramic radiographic measurements. Journal of dentistry 4:337-343.

Jagelaviciene, E. K., Ricardas; Krasauskiene, Aurelija (2010) The relationship between panoramic radiomorphometric indices of the mandible and calcaneus bone mineral density. Medicina (Kaunas, Lithuania) 2:95-103.

Johnell, O. \& Kanis, J. A. (2006) An estimate of the worldwide prevalence and disability associated with osteoporotic fractures. Osteoporosis international 17: 1726-1733.

Jonasson, G. (2009) Bone mass and trabecular pattern in the mandible as an indicator of skeletal osteopenia: A 10-year follow-up study. Oral Surgery Oral Medicine Oral Pathology Oral Radiology \& Endodontics 108: 284-291.

Jonasson, G. (2009) Bone mass and trabecular pattern in the mandible as an indicator of skeletal osteopenia: A 10-year follow-up study. Oral Surgery, Oral Medicine, Oral Pathology, Oral Radiology and Endodontology 2:284-291.

Jonasson, G., Bankvall, G. \& Kiliaridis, S. (2001) Estimation of skeletal bone mineral density by means of the trabecular pattern of the alveolar bone, its interdental thickness, and the bone mass of the mandible. Oral surgery, oral medicine, oral pathology, oral radiology, and endodontics 92: 346-352.

Jonasson, G. J., Lisa; Kiliaridis, Stavros (2007) Skeletal bone mineral density in relation to thickness, bone mass, and structure of the mandibular alveolar process in dentate men and women. European Journal of Oral Sciences 2:117-123. 
Kanis, J. A., McCloskey, E. V., Johansson, H., Cooper, C., Rizzoli, R. \& Reginster, J. Y. (2013) European guidance for the diagnosis and management of osteoporosis in postmenopausal women. Osteoporosis international 24: 23-57.

Kanis, J. A., Melton, L. J., 3rd, Christiansen, C., Johnston, C. C. \& Khaltaev, N. (1994) The diagnosis of osteoporosis. Journal of bone and mineral research 9: 1137-1141.

Khosla, S. (2013) Pathogenesis of age-related bone loss in humans. The journals of gerontology Series A, Biological sciences and medical sciences 68: 1226-1235.

Kingsmill, V. J. (1999) Post-extraction remodeling of the adult mandible. Crit Rev Oral Biol Med 10: 384-404.

Kingsmill, V. J. \& Boyde, A. (1999) Mineralization density and apparent density of bone in cranial and postcranial sites in the aging human. Osteoporosis international 9: 260-268.

Klemetti, E., Kolmakov, S., Heiskanen, P., Vainio, P. \& Lassila, V. (1993) Panoramic mandibular index and bone mineral densities in postmenopausal women. Oral surgery, oral medicine, and oral pathology 75: 774-779.

Klemetti, E., Vainio, P., Lassila, V. \& Alhava, E. (1993) Cortical bone mineral density in the mandible and osteoporosis status in postmenopausal women. Scandinavian Journal of Dental Research 101: 219-223.

Klemetti, E. V., P. (1993) Effect of bone mineral density in skeleton and mandible on extraction of teeth and clinical alveolar height. The Journal of prosthetic dentistry 1:21-25.

Klemetti, E. V., P.; Lassila, V.; Alhava, E. (1993) Trabecular bone mineral density of mandible and alveolar height in postmenopausal women. Scandinavian Journal of Dental Research 3:166-170.

Koh, K.-J. P., Ha-Na; Kim, Kyoung- A. (2012) Prediction of age-related osteoporosis using fractal analysis on panoramic radiographs. Imaging science in dentistry 4:231-235.

Kosugi, K., Yonezu, H., Kawashima, S., Honda, K., Arai, Y. \& Shibahara, T. (2013) A longitudinal study of the effect of experimental osteoporosis on bone trabecular structure in the rat mandibular condyle. Cranio 31: 140-150.

Kribbs, P. J. (1990) Comparison of mandibular bone in normal and osteoporotic women. The Journal of prosthetic dentistry 2:218-222.

Kribbs, P. J. (1992) Two-year changes in mandibular bone mass in an osteoporotic population. The Journal of prosthetic dentistry 5:653-655.

Kribbs, P. J., Chesnut, C. H., 3rd, Ott, S. M. \& Kilcoyne, R. F. (1989) Relationships between mandibular and skeletal bone in an osteoporotic population. The Journal of prosthetic dentistry $\mathbf{6 2}$ : 703-707.

Kribbs, P. J., Smith, D. E. \& Chesnut, C. H., 3rd (1983) Oral findings in osteoporosis. Part ii: Relationship between residual ridge and alveolar bone resorption and generalized skeletal osteopenia. The Journal of prosthetic dentistry 50: 719-724.

Kuroda, S., Mukohyama, H., Kondo, H., Aoki, K., Ohya, K., Ohyama, T. \& Kasugai, S. (2003) Bone mineral density of the mandible in ovariectomized rats: Analyses using dual energy $\mathrm{x}$-ray absorptiometry and peripheral quantitative computed tomography. Oral Dis 9: 24-28.

Lane, N., Armitage, G. C., Loomer, P., Hsieh, S., Majumdar, S., Wang, H. Y., Jeffcoat, M. \& Munoz, T. (2005) Bisphosphonate therapy improves the outcome of conventional periodontal treatment: Results of a 12-month, randomized, placebo-controlled study. Journal of periodontology 76: 11131122 . 
Law, A. N., Bollen, A. M. \& Chen, S. K. (1996) Detecting osteoporosis using dental radiographs: A comparison of four methods. Journal of the American Dental Association (1939) 127: 1734-1742.

Lee, B. D. W., Stuart C. (2005) Age and trabecular features of alveolar bone associated with osteoporosis. Oral surgery, oral medicine, oral pathology, oral radiology, and endodontics 1:92-98.

Lee, I. J. L., Jong Joo; Bae, Joon-Ho; Hwang, Eun; Lee, SeungJoo; Cho, Minhyuk; Kim, Joo Hyoung; Kim, Hyun Jun (2013) Significance of osteoporosis in facial bone density using computed tomography. The Journal of craniofacial surgery 2:428-431.

Lekholm, U., Zarb, G. \& Albrektsson, T. (1985) Patient selection and preparation. Tissue integrated prostheses. Chicago, Quintessence Publishing Co. Inc.: 199-209.

Li, N.-Y. Z., Fu-Ting; Jing, Heng; Bu, Ling-Xue; Yang, Xue-Cai; Feng, Yuan-Yong (2009) Measurement of mandible bone mineral density of adults in north china. Chinese journal of stomatology 7:425-429.

Li, N. J., H.; Li, J.; Zhou, F.; Bu, L.; Yang, X. (2011) Study of mandible bone mineral density of chinese adults by dual-energy x-ray absorptiometry. International journal of oral and maxillofacial surgery 11:1275-1279.

Lin, Z.-t. W., Tie-mei; Ge, Jiu-yu; Lin, Hua; Zhu, Xiu-fen (2010) Analysis of mandibular bone mineral density of senile osteoporosis patients. Chinese journal of stomatology 4:214-218.

Lindh, C., Horner, K., Jonasson, G., Olsson, P., Rohlin, M., Jacobs, R., Karayianni, K., van der Stelt, P., Adams, J., Marjanovic, E., Pavitt, S. \& Devlin, H. (2008) The use of visual assessment of dental radiographs for identifying women at risk of having osteoporosis: The osteodent project. Oral surgery, oral medicine, oral pathology, oral radiology, and endodontics 106: 285-293.

Looker, A. C., Wahner, H. W., Dunn, W. L., Calvo, M. S., Harris, T. B., Heyse, S. P., Johnston, C. C., Jr. \& Lindsay, R. (1998) Updated data on proximal femur bone mineral levels of us adults. Osteoporosis International 8: 468-489.

Lopez-Marcos, J. F., Garcia-Valle, S. \& Garcia-Iglesias, A. A. (2005) Periodontal aspects in menopausal women undergoing hormone replacement therapy. Medicina oral, patologia oral y cirugia bucal 10: 132-141.

Makker, A., Singh, M. M., Mishra, G., Singh, B. P., Jain, G. K. \& Jadhav, S. (2012) Relationship between bone turnover biomarkers, mandibular bone mineral density, and systemic skeletal bone mineral density in premenopausal and postmenopausal indian women. Menopause 19: 642-649.

Melton, L. J., 3rd, Chrischilles, E. A., Cooper, C., Lane, A. W. \& Riggs, B. L. (1992) Perspective. How many women have osteoporosis? Journal of bone and mineral research 7: 1005-1010.

Mohajery, M. \& Brooks, S. L. (1992) Oral radiographs in the detection of early signs of osteoporosis. Oral surgery, oral medicine, and oral pathology 73: 112-117.

Mohammad, A. R. A., M.; McNally, M. A. (1996) A pilot study of panoramic film density at selected sites in the mandible to predict osteoporosis. The International journal of prosthodontics 3:290-294.

Moher, D., Liberati, A., Tetzlaff, J., Altman, D. G. \& Group, P. (2009) Preferred reporting items for systematic reviews and meta-analyses: The prisma statement. Open Med 3: e123-130.

Munakata, M. T., N.; Honda, E.; Shiota, M.; Kasugai, S. (2011) Influence of menopause on mandibular bone quantity and quality in japanese women receiving dental implants. Archives of Osteoporosis 12:51-57.

Nackaerts, O. J., R.; Devlin, H.; Pavitt, S.; Bleyen, E.; Yan, B.; Borghs, H.; Lindh, C.; Karayianni, K.; van der Stelt, P.; Marjanovic, E.; Adams, J. E.; Horner, K. (2008) Osteoporosis detection using intraoral densitometry. Dentomaxillofacial Radiology 5:282-287. 
Naitoh, M. K., Yasunari; Inagaki, Koji; Katsumata, Akitoshi; Noguchi, Toshihide; Ariji, Eiichiro (2007) Assessment of mandibular buccal and lingual cortical bones in postmenopausal women. Oral Surgery, Oral Medicine, Oral Pathology, Oral Radiology, and Endodontics 4:545-550.

Nitta, H. I., Isao (2003) Skeletal and mandibular bone mineral density in dentate and edentulous postmenopausal women. Clinical calcium 5:e594-598.

Ozola, B., Slaidina, A., Laurina, L., Soboleva, U. \& Lejnieks, A. (2011) The influence of bone mineral density and body mass index on resorption of edentulous jaws. Stomatologija 13: 19-24.

Passos, J. S., Vianna, M. I., Gomes-Filho, I. S., Cruz, S. S., Barreto, M. L., Adan, L., Rosing, C. K., Cerqueira, E. M., Trindade, S. C. \& Coelho, J. M. (2013) Osteoporosis/osteopenia as an independent factor associated with periodontitis in postmenopausal women: A case-control study. Osteoporosis international 24: 1275-1283.

Payne, J. B. R., R. A.; Nummikoski, P. V.; Patil, K. D. (1999) Longitudinal alveolar bone loss in postmenopausal osteoporotic/osteopenic women. Osteoporosis international 1:34-40.

Pietrokovski, J., Starinsky, R., Arensburg, B. \& Kaffe, I. (2007) Morphologic characteristics of bony edentulous jaws. Journal of prosthodontics 16: 141-147.

Pluskiewicz, W. T., B.; Drozdzowska, B. (2000) Mandibular bone mineral density measured using dual-energy x-ray absorptiometry: Relationship to hip bone mineral density and quantitative ultrasound at calcaneus and hand phalanges. British Journal of Radiology 867:288-292.

Reginster, J. Y. \& Burlet, N. (2006) Osteoporosis: A still increasing prevalence. Bone 38: S4-9.

Ruttimann, U. E. W., R. L.; Hazelrig, J. B. (1992) Fractal dimension from radiographs of peridental alveolar bone. A possible diagnostic indicator of osteoporosis. Oral surgery, oral medicine, and oral pathology 1:98-110.

Seldin, E. B. (2012) Is there any reason to suspect that the determinants of mandibular bone mineral density might differ from those of systemic skeletal bone mineral density? Menopause 19: 608-609.

Shi, F. Y., S.; Xu, L. (1996) Measurement and analysis of bone mineral density of lumbar vertebrae and alveolar bone in patients with periodontitis. Chinese journal of stomatology 1:3-5.

Singhal, S., Chand, P., Singh, B. P., Singh, S. V., Rao, J., Shankar, R. \& Kumar, S. (2012) The effect of osteoporosis on residual ridge resorption and masticatory performance in denture wearers. Gerodontology 29: e1059-1066.

Southard, T. E. S., K. A. (1996) Detection of simulated osteoporosis in maxillae using radiographic texture analysis. IEEE Transactions on Biomedical Engineering 2:123-132.

Springe, B., A. Slaidina, U. Soboleva and A. Lejnieks (2014). Bone mineral density and mandibular residual ridge resorption. Int J Prosthodont 27: 270-276.

Streckfus, C. F. J., R. B.; Nick, T.; Tsao, A.; Tucci, M. (1997) Comparison of alveolar bone loss, alveolar bone density and second metacarpal bone density, salivary and gingival crevicular fluid interleukin-6 concentrations in healthy premenopausal and postmenopausal women on estrogen therapy. The journals of gerontology. Series A, Biological sciences and medical sciences 6:M343-351.

Taguchi, A. S., Y.; Ohtsuka, M.; Otani, K.; Tanimoto, K.; Hollender, L. G. (1999) Relationship between bone mineral density and tooth loss in elderly japanese women. Dentomaxillofacial radiology 4:219-223.

Taguchi, A. T., K.; Suei, Y.; Ohama, K.; Wada, T. (1996) Relationship between the mandibular and lumbar vertebral bone mineral density at different postmenopausal stages. Dentomaxillofacial radiology 3:130-135. 
Takaishi, Y., Okamoto, Y., Ikeo, T., Morii, H., Takeda, M., Hide, K., Arai, T. \& Nonaka, K. (2005) Correlations between periodontitis and loss of mandibular bone in relation to systemic bone changes in postmenopausal japanese women. Osteoporosis international 16: 1875-1882.

Tallgren, A. (2003) The continuing reduction of the residual alveolar ridges in complete denture wearers: A mixed-longitudinal study covering 25 years. 1972. The Journal of prosthetic dentistry $\mathbf{8 9}$ : 427-435.

Tanaka, M., Ejiri, S., Toyooka, E., Kohno, S. \& Ozawa, H. (2002) Effects of ovariectomy on trabecular structures of rat alveolar bone. Journal of periodontal research 37: 161-165.

Tomaszewski, T. (1997) Evaluation of mandible bone density by a radiovisiography method. Detecting osteoporotic changes. Medical Science Monitor 6:937-942.

Tomaszewski, T. (2002) Assessment of density and mandible bone structure in patients with generic osteoporosis symptoms. Annales Universitatis Mariae Curie-Sklodowska - Sectio d - Medicina 1:329341.

Tosoni, G. M. L., Alan G.; Cowan, Ann E.; Burleson, Joseph A. (2006) Pixel intensity and fractal analyses: Detecting osteoporosis in perimenopausal and postmenopausal women by using digital panoramic images. Oral Surgery, Oral Medicine, Oral Pathology, Oral Radiology, and Endodontics 2:235-241.

Tsolaki, I. N., P. N. Madianos and J. A. Vrotsos (2009). Outcomes of Dental Implants in Osteoporotic Patients. A Literature Review. Journal of Prosthodontics 18: 309-323.

Vishwanath, S. B., Kumar, V., Kumar, S., Shashikumar, P., Shashikumar, Y. \& Patel, P. V. (2011) Correlation of periodontal status and bone mineral density in postmenopausal women: A digital radiographic and quantitative ultrasound study. Indian Journal of Dental Research 22: 270-276.

von Wowern, N. (1974) A new method of gamma-ray osteodensitometry of the mandible. International Journal of Oral Surgery 3: 353-357.

von Wowern, N. (1988) Bone mineral content of mandibles: Normal reference values - rate of agerelated bone loss. Calcified Tissue International 4:193-198.

von Wowern, N. (2001) General and oral aspects of osteoporosis: A review. Clinical oral investigations 5: 71-82.

Yasar, F. A., F. (2006) The differences in panoramic mandibular indices and fractal dimension between patients with and without spinal osteoporosis. Dentomaxillofacial Radiology 1:1-9.

Zou, K. H., K. Tuncali and S. G. Silverman (2003). Correlation and simple linear regression. Radiology 227: 617-622. 
Table 1 Search strategy for Medline and Embase

Table 2 Reasons for exclusions of the 60 studies at the level of full-text screening

Table 3 Characteristics of the studies included in the systematic review. Correlation coefficient's confidence intervals were obtained through Fisher's z transformation. $\left(\mathrm{r}_{\mathrm{s}}\right.$ : Spearman's rank correlation coefficient; $\mathrm{r}$ : Pearson correlation coefficient; DXA: Dual-energy X-ray absorptiometry; QCT: Quantitative Computed Tomography; SPA: single photon absorptiometry; DPA: dual photon absorptiometry). * In the Klemetti et al study, the authors distinguished between the "most osteoporotic group", that had a BMD at femur neck $<920 \mathrm{mg} / \mathrm{cm}^{2}$, and the "average osteoporotic group", that had $920<\mathrm{BMD}<1040 \mathrm{mg} / \mathrm{cm}^{2}$.

Table 4 Assessment of methodological quality of the studies by the use of a tailored version of Newcastle-Ottawa Scale (NOS). A maximum of eleven stars could be assigned to each study.

Figure 1 Four-phase flow diagram of the article selection procedure, according to PRISMA statement (Moher, Liberati, Tetzlaff, Altman \& Group 2009). 
Table 1.

\begin{tabular}{|c|c|c|c|}
\hline \multicolumn{4}{|c|}{$\begin{array}{l}\text { MEDLINE via OVID (For Ovid OLDMEDLINE } 1946 \text { to 1965, Ovid MEDLINE In-Process \& Other Non-Indexed } \\
\text { Citations and Ovid MEDLINE } 1946 \text { to May 2013.) }\end{array}$} \\
\hline & Mesh terms & Free-text search & Limits \\
\hline Population & $\begin{array}{l}\text { bone disease, metabolic/ } \\
\text { or exp bone } \\
\text { demineralization, } \\
\text { pathologic/ or exp } \\
\text { osteoporosis }\end{array}$ & $\begin{array}{l}\text { osteoporo\$ OR } \\
\text { osteopeni\$ }\end{array}$ & $\begin{array}{l}\text { NOT (animals NOT } \\
\text { humans) }\end{array}$ \\
\hline Intervention/Exposure & $\begin{array}{l}\text { Bone Density OR exp } \\
\text { Densitometry } \\
\text { exp Jaw OR exp Jaw } \\
\text { Edentulous }\end{array}$ & $\begin{array}{l}\text { (bone adj2 densit\$) OR } \\
\text { (bone adj2 content) OR } \\
\text { bmd OR bmc OR } \\
\text { densitometr\$ } \\
\text { jaw\$ OR mandib\$ OR } \\
\text { maxill\$ or edentul\$ }\end{array}$ & \\
\hline \multicolumn{4}{|c|}{ EMBASE (from 1980 to May 2013) and EMBASE Classic (from 1947 to 1979): } \\
\hline & Emtree terms & Free-text search & Limits \\
\hline Population & $\begin{array}{l}\text { exp. osteoporosis OR } \\
\text { osteopenia }\end{array}$ & $\begin{array}{l}\text { osteoporo\$ OR } \\
\text { osteopeni\$ }\end{array}$ & $\begin{array}{l}\text { NOT (animals NOT } \\
\text { humans) }\end{array}$ \\
\hline Intervention/Exposure & $\begin{array}{l}\text { Bone Density OR Bone } \\
\text { densitometry } \\
\text { Jaw OR Edentulousness }\end{array}$ & $\begin{array}{l}\text { (bone adj2 densit\$) OR } \\
\text { (bone adj2 content) OR } \\
\text { bmd OR bmc OR } \\
\text { densitometr\$ } \\
\text { jaw\$ OR mandib\$ OR } \\
\text { maxill\$ or edentul\$ }\end{array}$ & \\
\hline
\end{tabular}


Table 2

\begin{tabular}{|c|c|}
\hline Author and year & Reasons for exclusion \\
\hline (Alman 2012) & No primary outcome reported \\
\hline (Alonso 2012) & No primary outcome reported \\
\hline (Amorim 2006) & No primary outcome reported \\
\hline (Amorim 2007) & Duplicate \\
\hline (Ardakani 2012) & No primary outcome reported \\
\hline (Bakalczuk 2006) & $\begin{array}{l}\text { Osteoporotic and non-osteoporotic subjects pooled together when measuring the } \\
\text { correlation coefficient }\end{array}$ \\
\hline (Bodic, Amouriq et al. 2012) & $\begin{array}{l}\text { Osteoporotic and non-osteoporotic subjects pooled together when measuring the } \\
\text { correlation coefficient }\end{array}$ \\
\hline (Bozic 2006) & No primary outcome reported \\
\hline (Buyukkaplan 2012) & No primary outcome reported \\
\hline (Byung 2005) & Duplicate \\
\hline (Devlin 2007) & No primary outcome reported \\
\hline $\begin{array}{l}\text { (Drozdzowska, Pluskiewicz } \\
\text { et al. 2002) }\end{array}$ & $\begin{array}{l}\text { Osteoporotic and non-osteoporotic subjects pooled together when measuring the } \\
\text { correlation coefficient }\end{array}$ \\
\hline (Erdogan, Incki et al. 2009) & $\begin{array}{l}\text { Osteoporotic and non-osteoporotic subjects pooled together when measuring the } \\
\text { correlation coefficient }\end{array}$ \\
\hline (Geraets 2008) & No primary outcome reported \\
\hline (Gulsahi, Paksoy et al. 2010) & $\begin{array}{l}\text { Osteoporotic and non-osteoporotic subjects pooled together when measuring the } \\
\text { correlation coefficient }\end{array}$ \\
\hline (Hedstrom 2010) & $\begin{array}{l}\text { Osteoporotic and non-osteoporotic subjects pooled together when measuring the } \\
\text { correlation coefficient }\end{array}$ \\
\hline (Holahan, Wiens et al. 2011) & $\begin{array}{l}\text { Osteoporotic and non-osteoporotic subjects pooled together when measuring the } \\
\text { correlation coefficient }\end{array}$ \\
\hline (Horner 1992) & No primary outcome reported \\
\hline (Horner, Devlin et al. 1996) & $\begin{array}{l}\text { Osteoporotic and non-osteoporotic subjects pooled together when measuring the } \\
\text { correlation coefficient }\end{array}$ \\
\hline (Horner 1998) & No primary outcome reported \\
\hline (Jagelaviciene 2010) & No primary outcome reported \\
\hline $\begin{array}{l}\text { (Jonasson, Bankvall et al. } \\
\text { 2001) }\end{array}$ & $\begin{array}{l}\text { Osteoporotic and non-osteoporotic subjects pooled together when measuring the } \\
\text { correlation coefficient }\end{array}$ \\
\hline (Jonasson 2007) & $\begin{array}{l}\text { Osteoporotic and non-osteoporotic subjects pooled together when measuring the } \\
\text { correlation coefficient }\end{array}$ \\
\hline (Jonasson 2009) & $\begin{array}{l}\text { Osteoporotic and non-osteoporotic subjects pooled together when measuring the } \\
\text { correlation coefficient }\end{array}$ \\
\hline (Kingsmill 1999) & $\begin{array}{l}\text { Osteoporotic and non-osteoporotic subjects pooled together when measuring the } \\
\text { correlation coefficient }\end{array}$ \\
\hline $\begin{array}{l}\text { (Klemetti, Kolmakov et al. } \\
\text { 1993) }\end{array}$ & $\begin{array}{l}\text { Osteoporotic and non-osteoporotic subjects pooled together when measuring the } \\
\text { correlation coefficient }\end{array}$ \\
\hline (Klemetti 1993) & No primary outcome reported \\
\hline (Klemetti 1993) & $\begin{array}{l}\text { Osteoporotic and non-osteoporotic subjects pooled together when measuring the } \\
\text { correlation coefficient }\end{array}$ \\
\hline (Koh 2012) & No primary outcome reported \\
\hline (Kribbs 1990) & No primary outcome reported \\
\hline (Kribbs 1992) & No primary outcome reported \\
\hline (Law, Bollen et al. 1996) & $\begin{array}{l}\text { Osteoporotic and non-osteoporotic subjects pooled together when measuring the } \\
\text { correlation coefficient }\end{array}$ \\
\hline (Lee 2005) & No primary outcome reported \\
\hline (Lee 2013) & No primary outcome reported \\
\hline (Li 2009) & No primary outcome reported \\
\hline (Li 2011) & No primary outcome reported \\
\hline (Lin 2010) & No primary outcome reported \\
\hline (Lindh, Horner et al. 2008) & No primary outcome reported \\
\hline (Makker, Singh et al. 2012) & No primary outcome reported \\
\hline (Mohajery and Brooks 1992) & $\begin{array}{l}\text { Osteoporotic and non-osteoporotic subjects pooled together when measuring the } \\
\text { correlation coefficient }\end{array}$ \\
\hline (Mohammad 1996) & No primary outcome reported \\
\hline (Munakata 2011) & No primary outcome reported \\
\hline (Nackaerts 2008) & No primary outcome reported \\
\hline (Naitoh 2007) & $\begin{array}{l}\text { Osteoporotic and non-osteoporotic subjects pooled together when measuring the } \\
\text { correlation coefficient }\end{array}$ \\
\hline (Nitta 2003) & $\begin{array}{l}\text { Osteoporotic and non-osteoporotic subjects pooled together when measuring the } \\
\text { correlation coefficient }\end{array}$ \\
\hline (Payne 1999) & No primary outcome reported \\
\hline
\end{tabular}


(Pluskiewicz 2000)

(Ruttimann 1992)

(Shi 1996)

(Southard 1996)

(Streckfus 1997)

(Taguchi 1996)

(Taguchi 1999)

(Takaishi, Okamoto et al. 2005)

(Tomaszewski 1997)

(Tomaszewski 2002)

(Tosoni 2006)

(Vishwanath, Kumar et al.

2011)

(Von Wowern 1988)
Osteoporotic and non-osteoporotic subjects pooled together when measuring the correlation coefficient

No primary outcome reported

No primary outcome reported

No primary outcome reported

Osteoporotic and non-osteoporotic subjects pooled together when measuring the correlation coefficient

Osteoporotic and non-osteoporotic subjects pooled together when measuring the correlation coefficient

No primary outcome reported

Osteoporotic and non-osteoporotic subjects pooled together when measuring the correlation coefficient

No primary outcome reported

No primary outcome reported

No primary outcome reported

Osteoporotic and non-osteoporotic subjects pooled together when measuring the correlation coefficient

Osteoporotic and non-osteoporotic subjects pooled together when measuring the correlation coefficient

No primary outcome reported 
Table 3

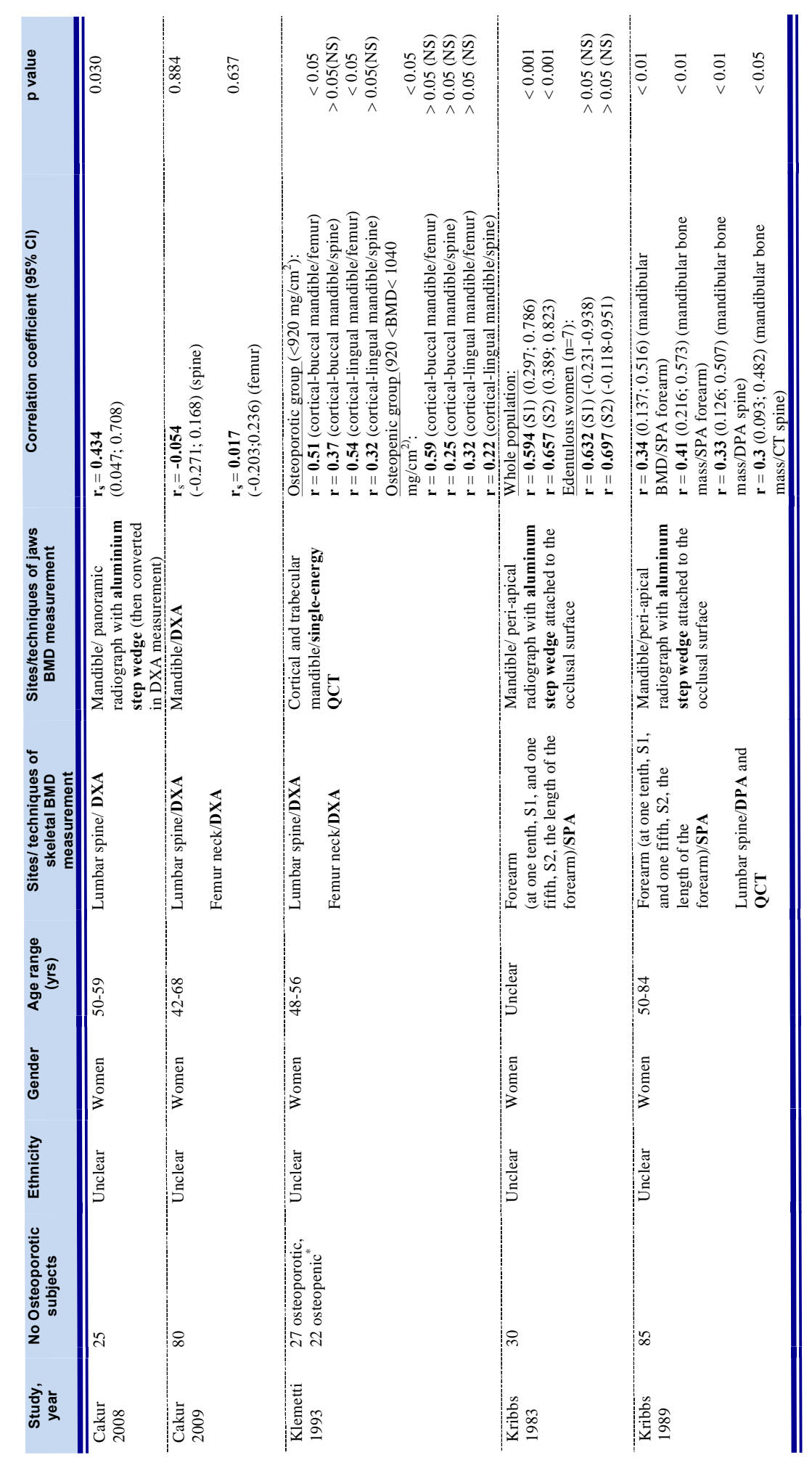


Table 4

\begin{tabular}{|c|c|c|c|c|c|c|}
\hline & & $\begin{array}{l}\text { Cakur } \\
2008\end{array}$ & $\begin{array}{l}\text { Cakur } \\
2009\end{array}$ & $\begin{array}{l}\text { Klemetti } \\
1993\end{array}$ & $\begin{array}{l}\text { Kribbs } \\
1983\end{array}$ & $\begin{array}{l}\text { Kribbs } \\
1989\end{array}$ \\
\hline $\begin{array}{l}\text { SELECTION } \\
(\max 2 \text { stars })\end{array}$ & $\begin{array}{l}\text { Ascertainment of the exposure } \\
\text { (osteoporosis): } \\
\text { a) Validated measurement tool for } \\
\text { BMD (WHO guidelines or National } \\
\text { Society guidelines)* } \\
\text { b) Non-validated measurement } \\
\text { tool/self-report/unclear } \\
\text { Representativeness of the } \\
\text { subjects (osteoporotic subjects): } \\
\text { a) Truly representative of the average } \\
\text { in the target population. * (random or } \\
\text { consecutive sampling) } \\
\text { b) Potential for selection bias or no } \\
\text { description of the sampling strategy }\end{array}$ & & & & & \\
\hline $\begin{array}{l}\text { COMPARABILITY } \\
(\max 2 \text { stars })\end{array}$ & $\begin{array}{l}\text { Confounding factors are } \\
\text { controlled. } \\
\text { a) The study controls for concomitant } \\
\text { diseases affecting bone metabolism. * } \\
\text { b) The study control for any } \\
\text { additional factor (e.g. Medications). * } \\
\text { c) No factors are controlled/Not } \\
\text { specified }\end{array}$ & & & & & \\
\hline $\begin{array}{l}\text { EXPOSURE } \\
(\max 7 \text { stars })\end{array}$ & $\begin{array}{l}\text { Ascertainment of jaw bone } \\
\text { density: } \\
\text { a) The method is well-described, } \\
\text { calibration of the technique is reported } \\
\text { and the examiner(s) is blinded to } \\
\text { skeletal BMD** } \\
\text { b) The method is well-described but } \\
\text { the blindness of operators and/or the } \\
\text { calibration of the technique are not } \\
\text { reported * } \\
\text { c) Subjective evaluation/ Not } \\
\text { specified } \\
\text { Ascertainment of skeletal bone } \\
\text { density: } \\
\text { a) Validated measurement tool (DXA } \\
\text { scan)** } \\
\text { b) Non-validated measurement tool } \\
\text { but the method is well-described and } \\
\text { calibration is reported* } \\
\text { c) Subjective evaluation/ Not } \\
\text { specified/Not well described } \\
\text { measurement tool } \\
\text { The same method of } \\
\text { ascertainment was used to } \\
\text { measure skeletal and jaw bone } \\
\text { mineral density } \\
\text { a) Yes * } \\
\text { b) No/ Not specified } \\
\text { Statistical test: } \\
\text { a) The statistical test used to analyze } \\
\text { the data is clearly described and } \\
\text { appropriate, and the measurement of } \\
\text { the association is presented, including } \\
\text { the probability level (p value)* } \\
\text { b) The statistical test is not } \\
\text { appropriate, not described or } \\
\text { incomplete/ insufficient } \\
\text { Interval time between } \\
\text { ascertainment of skeletal and } \\
\text { jaw bone density: } \\
\text { a) Reported and appropriate (within } \\
12 \text { months)* } \\
\text { b) Not reported/Not appropriate } \\
\end{array}$ & & 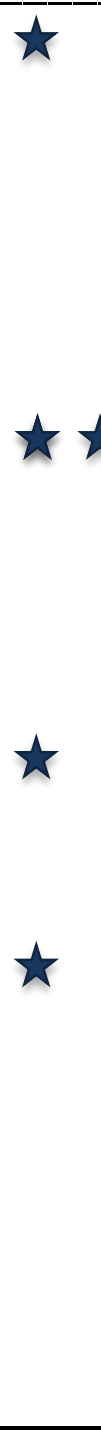 & $\gamma$ & $\begin{array}{l}\text { (reference to } \\
\text { a previous } \\
\text { paper) }\end{array}$ & $\begin{array}{l}\text { to } \\
\text { (reference to } \\
\text { a previous } \\
\text { paper) }\end{array}$ \\
\hline
\end{tabular}

